\title{
Early childhood caries and oral health care of Hong Kong preschool children
}

This article was published in the following Dove Medical Press journal: Clinical, Cosmetic and Investigational Dentistry

\section{Kitty Jieyi Chen \\ Sherry Shiqian Gao \\ Duangporn Duangthip \\ Edward Chin Man Lo \\ Chun Hung Chu}

Faculty of Dentistry, The University of Hong Kong, Sai Ying Pun, Hong Kong
Correspondence: Chun Hung Chu Faculty of Dentistry, The University of Hong Kong, 34 Hospital Road, Sai Ying Pun, Hong Kong

Tel +85228590287

Email chchu@hku.hk

\begin{abstract}
Surveys have shown that the prevalence of early childhood caries (ECC) among 5-year-old children decreased from 63\% in 1993 to 55\% in 2017. Caries experience was unevenly distributed; $81 \%$ of the caries lesions were found in $26 \%$ of the children. Risk factors, including oral hygiene practice behaviors, sugar consumption, parental oral health-related knowledge, and sociodemographic backgrounds, were significantly related to ECC. Oral health promotion aimed at managing the burden of ECC has been implemented. Water fluoridation was launched in 1961, and the fluoride concentration has been adjusted to $0.5 \mathrm{ppm}$ since 1988 . It is considered an important dental public health measure in Hong Kong. The Department of Health set up the Oral Health Education Unit in 1989 to deliver oral health education to further improve the oral health of preschool children. Other nongovernmental organizations also launched short-term oral health promotion programs for preschool children. However, no significant change in the prevalence of ECC has been observed in the recent two decades. There is a necessity to revisit dental public health policies and develop effective evidence-based strategies to encourage changes in oral health-related behaviors to forestall the impending epidemic of ECC in Hong Kong.
\end{abstract}

Keywords: caries, oral health, children, Hong Kong

\section{Introduction}

Hong Kong SAR, officially the Hong Kong Special Administrative Region of the People's Republic of China, is an autonomous territory that maintains a separate legislature, executive, and judiciary from Mainland China. It is located on the southeastern coast of Mainland China. Hong Kong had been a colony of the British Empire since 1842 and was returned to China in 1997. The Sino-British Joint Declaration has guaranteed Hong Kong capitalist economic system and autonomous government for 50 years after the transfer of sovereignty. ${ }^{1}$

The level of social and economic development of Hong Kong and China is different. Compared to Mainland China, Hong Kong had a higher human development index (0.91 vs 0.74$)$, including higher lifespan, higher education level, and higher gross domestic product (GDP) per capita. ${ }^{2}$ In 2017, the GDP per capital of Hong Kong was 46,228 USD, while that of Mainland China was 8,830 USD. ${ }^{3,4}$ However, Hong Kong had lower GDP per capita when compared to that of the US, which reached 59,484 USD in $2017 . .^{5}$ The total expenditure on health care was around $6 \%$ of the GDP in Hong Kong. ${ }^{6}$

In Hong Kong, there are 7.4 million residents residing in an area of 1,104 sq km. ${ }^{7}$ Hong Kong was ranked the fourth most densely populated place in the world in $2017 .{ }^{8}$ 
According to the 2016 census, $92 \%$ of the Hong Kong population is ethnic Chinese, and $8 \%$ consists of other ethnic groups, including a large number of Filipino and Indonesian foreign domestic helpers. Nearly $9 \%$ of the ethnic minorities were under 15 years old. ${ }^{9}$ In 2016, there were 344,894 preschool children ( $0-5$ years old) in Hong Kong. ${ }^{10}$ More than $90 \%$ of the 3- to 5-year-old children attend kindergartens, whereas home schooling is uncommon in Hong Kong. ${ }^{11}$

Oral health is an important part of general health. Oral health has influences on children's lives and future development. To plan the appropriate oral health promotion schemes, it is necessary for health policy makers and dental practitioners to understand the updated Hong Kong children's caries situation, its risk factors, and the effectiveness of the existing programs. The aim of the present review is to describe the dental caries status, its risk factors, and oral health care programs for preschool children in Hong Kong.

\section{Method}

Publications related to the oral health status of preschool children in Hong Kong, government-archived reports, and information of dental care were retrieved from electronic databases (PubMed and Scopus) and hand searches. Dental caries experience, related risk factors, and oral health promotion programs were reviewed.

\section{Dental caries status}

Early childhood caries (ECC) is defined as the presence of one or more decayed, missing, or filled tooth surfaces in any primary tooth in a child younger than 71 months of age. ${ }^{12}$ ECC is the most common chronic disease among preschool children. It was ranked as the 12 th most prevalent condition and affected around 560 million children worldwide, as reported by the 2015 Global Burden of Disease Study. ${ }^{13}$ Although no symptoms can be found at the early stage, ECC may cause discomfort or pain if the lesion involves the dental pulp. Moreover, it may also cause difficulties in sleeping and eating and may have an effect on children's growth and school performance. ${ }^{14}$

In Hong Kong, the first epidemiological study that reported the dental caries status of preschool children was conducted in 1968 by the Medical and Health Department and WHO. The results showed that the ECC prevalence in 5- to 6-year-old preschool children was $87 \% .{ }^{15}$ The second epidemiological survey was conducted in 1993, reporting that the prevalence of ECC among 5-year-old children decreased to $63 \%$ with a decayed, missing and filled teeth (dmft) score of 3.2. ${ }^{16}$ The situation of caries status in preschool children remains unsatisfactory. Several epidemiological studies were conducted in the past two decades. They reported that caries prevalence was $\sim 48 \%-56 \%$ and that the mean $\mathrm{dmft}$ score ranged from 1.8 to 2.7. ${ }^{17-21}$ According to the results of the latest territory-wide survey conducted in 2011, ECC was unevenly distributed. A small proportion (26\%) of individuals carried most $(81 \%)$ of the decay experience. ${ }^{20}$ Approximately, one in six children (17\%) aged 5 years had six or more decayed teeth. ${ }^{20}$ A recent study published in 2017 indicated that no significant improvement was observed, compared with the territory-wide survey in 2011. ECC remained prevalent (55\%) among 5-year-old children, and their mean dmft score was $2.7 .{ }^{21}$ In addition, most of the decayed teeth $(>90 \%)$ were untreated. ${ }^{21}$

In summary, approximately half of the 5-year-old children are still suffering from ECC, and the distribution of dental caries is uneven among preschool children. ${ }^{20}$ The summary of the dental caries situation of preschool children in Hong Kong is presented in Table 1 and Figure 1.

Table I Early childhood caries (ECC) in Hong Kong preschool children

\begin{tabular}{|c|c|c|c|c|}
\hline Author (years of conduct) [Ref] & Age (years) & Sample size & ECC prevalence & Mean dmft \\
\hline Wong $(1968)^{15 a}$ & $5-6$ & - & $87 \%$ & 5.3 \\
\hline Wei et al (1993) ${ }^{16 a}$ & 5 & 1,105 & $63 \%$ & 3.2 \\
\hline \multirow[t]{2}{*}{ Chu et al (1999) $)^{17 a}$} & 4 & 240 & $36 \%$ & 0.9 \\
\hline & 5 & 367 & $56 \%$ & 1.8 \\
\hline Department of Health $(200 \mathrm{I})^{18}$ & 5 & 67,300 & $51 \%$ & 2.3 \\
\hline \multirow[t]{2}{*}{ Chu et al (2009) $)^{19}$} & 4 & 239 & $41 \%$ & 1.9 \\
\hline & 5 & 338 & $48 \%$ & 2.3 \\
\hline Department of Health $(20 \mathrm{II})^{20}$ & 5 & 52,300 & $51 \%$ & 2.5 \\
\hline Chen et al $(2016)^{2 !}$ & 5 & 505 & $55 \%$ & 2.7 \\
\hline
\end{tabular}

Note: ${ }^{a}$ Year of publication was presented instead because year of conduct was not specified.

Abbreviations: ECC, early childhood caries; dmft, decayed, missing and filled teeth. 


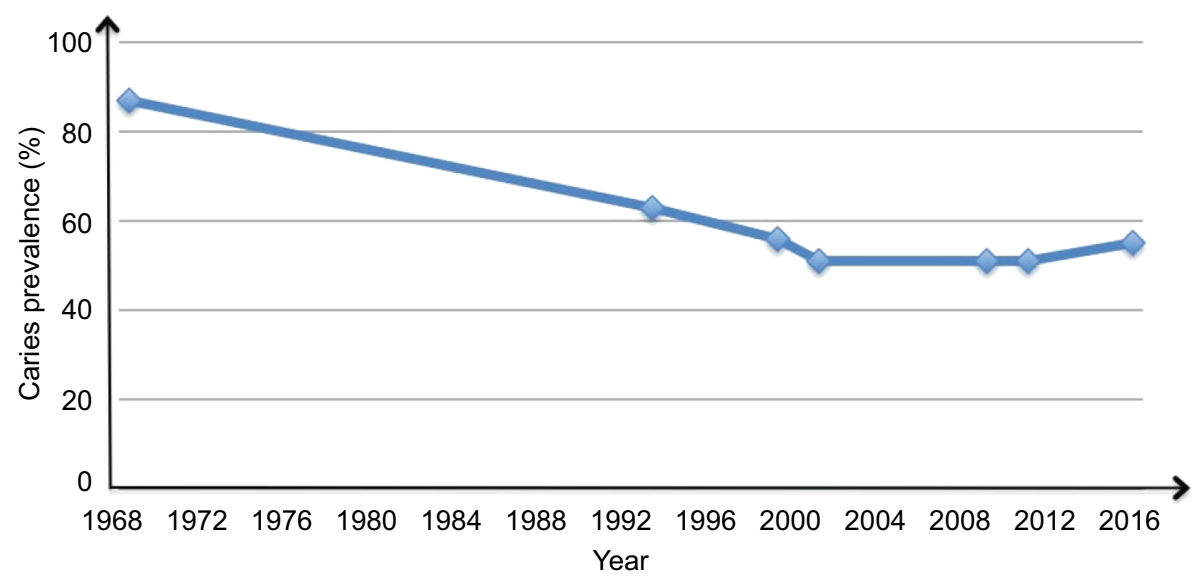

Figure I Prevalence of early childhood caries among 5-year-old Hong Kong children.

\section{Risk factors}

It is necessary to understand the risk factors related to dental caries when planning and implementing programs to improve the oral health situation of preschool children. Four etiological factors, which are susceptible host, cariogenic bacteria, fermentable carbohydrate substrate, and time, are well documented. Other environmental risk factors, including the use of fluoride, parental oral health-related knowledge, access to dental care service, and sociodemographic background were also found to have a relationship with ECC among preschool children in Hong Kong.

\section{Tooth brushing}

Tooth brushing is one of the essential dental caries prevention strategies. Prior to the eruption of the first primary teeth, caregivers are asked to clean the infant's gum with moist gauze or a washcloth wrapped around the finger. From the eruption of the first tooth to age 2 years, children are recommended to have their teeth cleaned with a soft toothbrush with toothpaste. At age 2-6 years, a child can begin to use a pea-sized amount of fluoride toothpaste and brush his or her teeth twice daily. ${ }^{22}$

As reported by the two territory-wide surveys in Hong Kong conducted in 2001 and 2011, there was an increase in tooth brushing frequency among 5-year-old children. In $2011,70.6 \%$ of the children brushed their teeth twice daily, whereas $3.9 \%$ of them brushed three times or more. ${ }^{20} \mathrm{In}$ $2001,53.0 \%$ and $1.4 \%$ of them did, respectively. ${ }^{18}$ However, $4.7 \%$ of children were still brushing their teeth less than once daily in 2011. ${ }^{18,20}$ Moreover, the recent survey in 2017 showed that $30.5 \%$ of the children had never brushed their teeth before the age of 2 years. Over $70 \%$ of the caregivers reported that they assisted their children in performing tooth brushing daily. ${ }^{21}$

\section{Sugar consumption}

Fermentable carbohydrates are a key factor in caries development. Cariogenic bacteria produce acids after sugar intake and subsequently demineralize the tooth surface. A positive relationship can be found between the length of exposure time of the teeth to sugar and dental caries. The frequent intake of sugary snacks could lengthen the time of exposure. ${ }^{23}$ Results of the recent epidemiological studies in Hong Kong indicated that $40 \%$ of the 5 -year-old children who had snacked on sugary food twice or more daily had statistically significant higher caries prevalence, when compared to those who snacked less than twice daily. ${ }^{19,21}$ Only one-third (35.6\%) of the 5-year-old children did not have a daily snacking habit, as reported by the 2011 survey. ${ }^{20}$ Nowadays, refined sugar is widely available in grocery stores in Hong Kong. Caregivers may indulge their young children with sweets that lead to the excessive intake of sugar.

\section{Use of fluoride}

There is evidence that both systemic and topical uses of fluoride are beneficial for caries prevention. ${ }^{24}$ In Hong Kong, water fluoridation was implemented in the early 1960s. At present, all Hong Kong residents (100\%) usually consume fluoridated tap water daily. ${ }^{25}$ Fluoride toothpaste is commercially available and is affordable to most of the families in Hong Kong. It is suggested that children can start tooth brushing with fluoride toothpaste at the age of 2 years. The results of the 2011 territory-wide survey study showed that the majority $(94.3 \%)$ of the children in Hong Kong used toothpaste. ${ }^{20}$ However, only half of the parents indicated that their children used fluoridated toothpaste, while one-third did not know whether their children's toothpastes contained fluoride. ${ }^{20}$ Nevertheless, most of them (74.7\%) reported that they understood the benefit of fluoride on caries prevention. ${ }^{20}$ 


\section{Parental oral health-related knowledge}

Studies have found that there was a relationship between parental oral health-related knowledge and dental caries prevalence. ${ }^{19-21}$ Children whose parents had better oral health literacy had lower dental caries prevalence. ${ }^{21}$ After comparing the 2001 and 2011 territory-wide surveys, there was an improvement in parental oral health-related knowledge related to the risk factors of dental caries and gum diseases. Nearly all of the parents (95.4\%) understood that the overconsumption of sugary snacks increased the risk of dental caries, and $58.3 \%$ of them perceived that brushing with fluoride-free toothpaste was another risk factor. ${ }^{20}$ Around one-third of the parents $(28.9 \%)$ misunderstood that a lack of calcium would increase the risk of tooth decay. ${ }^{20}$

\section{Access to dental care}

Although children are asked to have their teeth checked as early as $6-12$ months old, $75.4 \%$ of the parents reported that their 5-year-old preschool children had never visited a dentist. ${ }^{21}$ Besides, it was found that children who had dental attendance experience had significantly higher dental caries prevalence. ${ }^{21}$ The reason for that might be attributed to problem-oriented dental care-seeking behavior. As reported by the 2011 survey, half of the children (48.3\%) visited a dentist due to their dental problems such as tooth decay, toothache, and trauma. ${ }^{20}$ For those children who had dental attendance experience, less than half of the parents (44.9\%) preferred to have the decayed teeth of their children restored, whereas $11.1 \%$ parents preferred to leave the decayed teeth untreated. ${ }^{20}$

\section{Sociodemographic background}

There are a number of studies showing that socioeconomic factors are related to children's dental caries experience. ${ }^{16,17,19,21}$ From 1993 to 2017, all oral health surveys concluded that household income was significantly associated with preschool children's dental caries experience. Children from families with higher income and whose parents had a higher education level had lower dental caries prevalence. These results indicated that social inequality exists among the dental health of preschool children in Hong Kong. Underprivileged children may have a higher risk of developing caries lesions. Besides, the demographic characteristics also affect the dental caries experience. As Hong Kong was colonized by the British Empire, its culture, foods, and living lifestyles are slightly different from Mainland China. The epidemiological survey conducted in 2009 reported that children who were born in Mainland China had significantly higher dental caries experience than those born in Hong Kong. ${ }^{16}$
In addition, there has been a change in the legislation that influenced the demographic characteristics of Hong Kong children. Since 2001, babies born in Hong Kong from Mainland women whose spouses are not Hong Kong Permanent Residents were entitled "Type II Babies". They have the right of residency in Hong Kong as well as the opportunity to benefit from Hong Kong's education and health care system. After that, the number of Type II Babies increased significantly from 620 in 2001 to 35,736 in 2011, and the number of live births increased from 48,219 to $95,451 .^{26}$ Although Hong Kong was recognized as one of the lowest birth rate districts/countries in the world at the end of the 20th century, the number of births dramatically increased between 2001 and 2011 because of this policy. As a result, Hong Kong's health care services were under great pressure. Studies conducted in 2009, 2011, and 2016 indicated that the ECC prevalence of preschool children slightly increased compared to that in 2001. ${ }^{19-21}$

To solve this problem, the Hong Kong government implemented the zero-quota policy on obstetric services for Mainland women whose spouses were not Hong Kong residents in 2013. Type II babies were no longer entitled to have the right of residency in Hong Kong since then. Therefore, the number of Type II Babies decreased to 823, and the number of live births decreased to 62,305 in $2014 .{ }^{26}$ The influence of this demographic policy on the situation of ECC must be monitored in a future epidemiological study.

The summary of significant risk factors studied in Hong Kong is presented in Table 2. Based on the recent studies conducted in 2009 and 2016, similar caries risk factors were found. Low family income, frequent snacking habits, and low level of parental dental knowledge were the significant factors remaining in the final model of multivariate analyses. A primary prevention program should aim to encourage changes in dietary behaviors and improve parental knowledge about child oral health. In addition, underprivileged children who come from low-income families should be prioritized.

\section{Oral health care programs}

According to these risk factors, there were several oral health promotion programs that have been launched to control the disease and improve the oral health status of preschool children.

\section{Water fluoridation}

Water fluoridation is the controlled addition of fluoride to a public water supply, which aims to prevent dental caries. Results of the recent Cochrane review showed that the 
Table 2 Risk factors of early childhood caries reported by surveys in Hong Kong

\begin{tabular}{|c|c|c|c|c|}
\hline \multirow[t]{2}{*}{ Risk factors } & 1993 & 1999 & 2009 & 2016 \\
\hline & $\begin{array}{l}\text { Wei et } \mathrm{al}^{16} \\
(\mathrm{~N}=1,105)\end{array}$ & $\begin{array}{l}\text { Chu et } \mathrm{al}^{17} \\
(\mathrm{~N}=607)\end{array}$ & $\begin{array}{l}\text { Chu et } \mathrm{al}^{19} \\
(\mathrm{~N}=557)\end{array}$ & $\begin{array}{l}\text { Chen et } \mathrm{al}^{2} \\
(\mathrm{~N}=505)\end{array}$ \\
\hline Monthly household income & Yes & Yes & Yes & Yes \\
\hline Tooth brushing frequency & Yes & Yes & No & No \\
\hline Fathers' profession & Yes & - & - & - \\
\hline Place of birth & - & Yes & Yes & No \\
\hline Response of dental care to children's caries & - & Yes & - & - \\
\hline Dental visit pattern & - & Yes & Yes & Yes \\
\hline Mother's education level & - & Yes & Yes & Yes \\
\hline Father's education level & - & Yes & Yes & No \\
\hline Age tooth brushing started & - & - & Yes & No \\
\hline Snacking frequency & - & - & Yes & Yes \\
\hline Parents' dental knowledge level & - & Yes & Yes & Yes \\
\hline Parenthood & - & - & Yes & No \\
\hline Primary caregiver & - & - & Yes & Yes \\
\hline
\end{tabular}

Notes: Yes: the risk factor was significantly associated with ECC; No: the risk factor was not significantly associated with ECC; -: the risk factor was not reported in the study.

Abbreviation: ECC, early childhood caries.

introduction of water fluoridation resulted in a 35\% reduction in caries experience ( $\mathrm{dmft}$ score) ${ }^{27}$ The first community water fluoridation program to prevent caries was launched in Michigan, US, in $1945 .{ }^{28}$ It was ranked as one of the ten great public health achievements of the 20th century in the US by the Centers for Disease Control and Prevention. ${ }^{29}$ It was reported that there were 25 countries/districts that had water fluoridation programs around the world in 2012, and Hong Kong was the only place where $100 \%$ of the population consumed fluoridated water. ${ }^{25}$

In Hong Kong, the water fluoridation program was introduced in 1960 with a fluoride level of 0.8 parts per million (ppm). After that, the mean dmft score of the 12-year-old children decreased dramatically from 4.4 in 1960 to 1.5 in $1968 .{ }^{15,30}$ Subsequently, the concentration of fluoride increased to $1.0 \mathrm{ppm}$ in $1976 .{ }^{31}$ However, the results of this survey indicated that the prevalence of dental fluorosis among 7 - to 12 -year-old children also increased to $64 \%{ }^{30}$ Therefore, the concentration was adjusted to be $0.7 \mathrm{ppm}$ in 1986. Later, the epidemiological survey in 1988 reported that the dental fluorosis remained prevalent (47\%). Then, the concentration of fluoride was reduced to $0.5 \mathrm{ppm}$ in $1988 .{ }^{32}$ Until now, the fluoride level has remained at $0.5 \mathrm{ppm}$ in Hong Kong. Optimal fluoride concentration in drinking water was determined by various factors including environmental temperature, daily water consumption, and access to different sources of fluoride. ${ }^{33}$ The amount of fluoride ingested during the summer time was higher than that during the winter time. ${ }^{34}$ For people living in tropical or subtropical regions like in Hong Kong, they tend to consume more water than those living in cooler regions. ${ }^{34}$ Besides, young children may be at risk of ingesting fluoride from toothpaste which is commercially available and affordable for most of the families. Therefore, the fluoride concentration in Hong Kong has been adjusted to be $0.5 \mathrm{ppm}$, which is lower than that in the cooler areas such as in the US $(0.7 \mathrm{ppm}) .{ }^{35}$ Although water fluoridation is one of the most significant dental public health projects benefitting all residents in Hong Kong, the caries statuses of preschool children were unsatisfactory. Additional effective evidence-based oral health programs for preschool children are needed.

\section{Oral health education}

The Oral Health Education Unit (OHEU) was set up by the Department of Health in 1989, with the main aim of improving the oral health status of Hong Kong children. ${ }^{36}$ The OHEU has developed oral health literatures for different age groups and organized community-based oral health projects. The "Brighter Smiles for the New Generation" program was implemented by OHEU targeting 3- to 5-year-old children who studied in local kindergartens and nurseries. ${ }^{37}$ It aims to help young children establish tooth brushing habits and healthy eating habits. Educational materials including teacher's manuals, student handbooks, oral health education VCDs, and posters were provided to the participating kindergartens with the aim of improving the oral health knowledge of teachers, parents, and children. ${ }^{37}$ It was reported that this program could reach $\sim 600$ kindergartens $(60 \%)$ in Hong Kong. ${ }^{38}$ In each year, the number of participating children was estimated to be $\sim 100,000 .{ }^{38}$ Besides, the Brighter Smiles 
Playland was launched to provide free dental facilities and interactive games for 4-year-old students in kindergartens. ${ }^{39}$ Classes are provided to teach children about tooth brushing and oral health-related knowledge. A website called "Tooth Club", which contains the information on oral health for the general population, was also established by the OHEU. ${ }^{36}$ The oral health information and materials can be downloaded without any charge if needed.

\section{Community dental services}

A number of nongovernmental organizations (NGOs) in Hong Kong are operated by non-profit-making social service agencies, religious groups, labor unions, and so on. They mostly provide direct and indirect health or educational services to citizens. Some of them provide dental care services for Hong Kong residents. For example, Project Concern Hong Kong, one of the non-profit NGOs providing health services for people with low income, has initiated a project named "Smiley Action Days" since 2014. ${ }^{40}$ This project aimed to enhance the oral health, dental knowledge, and self-care ability of Hong Kong citizens in different districts by empowering the dental care team of the mobile dental clinics to provide basic and preventive dental care. A large-scale oral health promotion public event comprising mobile dental services was held in different districts. ${ }^{41}$ Children in the selected districts could enroll and received the dental examination, topical fluoride treatment, and oral health education on the mobile public event. ${ }^{41}$ However, this short-term project can only benefit a small portion of preschool children in Hong Kong.

Faculty of Dentistry, The University of Hong Kong, the only dental school in Hong Kong, has implemented the "Preschool Oral Health Programme" for preschool children. ${ }^{42} \mathrm{~A}$ pilot program was started in 2008 and provided free dental care services for 19 kindergartens. Two years later, the project was expanded, covering over 100 kindergartens. ${ }^{43}$ Several oral health promotion activities have been done, such as an oral health education workshop for teachers. Oral health education materials including dental models, posters, and booklets are provided to participating schools. Lectures and seminars for parents are also organized in a school hall. Moreover, this program also provides oral examination and topical fluoride (silver diamine fluoride or SDF) for caries control in a school-based setting. ${ }^{42}$ Several randomized clinical trials evaluated the effectiveness of SDF in arresting dentine caries in preschool children in Hong Kong. A 30-month clinical trial reported that the caries arrest rates were $55.2 \%$ and $66.9 \%$ when $12 \%$ and $38 \%$ SDF annually were applied, respectively. ${ }^{44}$ Another 30 -month study showed that $48 \%$ of the decayed surfaces became arrested when 30\% SDF was applied annually. ${ }^{45}$ These data indicated that SDF treatment can benefit preschool children, especially the ones with established dental caries.

\section{Discussion}

After the initiation of water fluoridation in 1961, there was a significant improvement regarding the oral health status of preschool children in Hong Kong during the 1960s to 1990s. However, the overall caries status of preschool children has remained unchanged in the last two decades. The latest oral health survey showed that $55 \%$ of the 5 -year-old children had dental caries. In Mainland China and Taiwan, where the majority ethnic group was also Chinese, the prevalence of dental caries among 5-year-old children was $79 \%$ and $81 \%$, respectively. ${ }^{46,47}$ However, when compared to its counterparts in terms of economic development, the situation in Hong Kong remained unsatisfactory. For example, in the UK, the prevalence of dental caries of 5-year-old children ranged from $27 \%$ to $41 \%$ in 2014 , whereas the prevalence was $44 \%$ in 2015 in Australia. ${ }^{48,49}$ The unsatisfactory ECC situation in Hong Kong may be due to the deficiencies of the current oral health care system in delivering accessible preventive and curative dental services to preschool children in Hong Kong. Although several oral health promotion programs have been launched, misconceptions about the importance of primary dentition and misunderstandings regarding the risk factors of ECC remained commonly found among Hong Kong parents. ${ }^{20}$ There still exist areas for continued improvement regarding the oral hygiene practices and parents' oral healthrelated knowledge in future projects. In addition, dental caries is caused by similar modifiable risk factors of other non-communicable diseases. For example, excessive sugar consumption could increase the risk of diabetes and dental caries. Rather than focusing on individualistic approaches, a common risk approach should be adopted to resolve both the dental and general health problem. ${ }^{50}$ Child oral health programs should be integrated with other public health sectors. The collaboration and empowerment of stakeholders in dental care services for young children should be built and strengthened.

Community-based dental care services should be expanded in Hong Kong to deal with the burden of dental caries. Although some NGOs have provided dental services to residents with low income, most of the projects were implemented in the short-term period and benefitted a small portion of the child population. At present, the Hong Kong government provides only emergency dental services for the 
general population, including preschool children, in eleven dental clinics around Hong Kong. ${ }^{51}$ There is no governmentsubsidized dental care service, specifically for preschool children. The dental visit or dental treatment is generally selffinanced. Free oral examination, preventive dental treatment, and basic restorative dental treatment are provided only for the schoolchildren (6-12 years old) who have paid US\$ 2.50 (HK\$ 20) annually. There are eight governmental clinics in total to serve the school children. As there is no regulation regarding the dental fees in Hong Kong following the "free trade" policy, the dental treatment fees vary among clinics and are unaffordable for many families. This may be why the utilization of dental services by preschool children was low.

Effective evidenced-based oral health programs including supervised tooth brushing program and topical fluoride application in a school setting should be established to improve the oral health of Hong Kong preschool children. The successful story of supervised tooth brushing program from Scotland can be an example. The governmental dental care program called Childsmile was launched in 2005. This program has provided a free-flow feeder cup to children by the age of 1 year. A supervised tooth brushing program complemented with a free set of toothbrush and toothpaste has been offered to nursery children. ${ }^{52}$ Results of the epidemiological studies showed that caries prevalence of 5-year-old children in Scotland reduced from $46 \%$ in 2005 to $32 \%$ in 2013 , and the mean dmft score decreased from 2.2 to $1.3 .{ }^{53,54}$ In addition, results of several systematic reviews show that use of SDF in a school setting is effective in arresting dental caries among preschool children. ${ }^{55,56} \mathrm{~A}$ new guideline issued by the American Academy of Pediatric Dentistry supports the use of SDF as part of a comprehensive caries management program for young children. ${ }^{57}$ Thus, SDF treatment for children complemented with dental health education and counseling to the parents would be very beneficial in improving child oral health, particularly for children with high caries risk.

Moreover, there is a shortage of dental resources, especially pediatric dentists in Hong Kong. In 2018, there were around 2,552 registered dentists in Hong Kong, and the dentist-to-population ratio was $1: 2,900 .{ }^{7,58} \mathrm{~A}$ majority of registered dentists (89\%) are general practitioners, whereas there are only 36 registered pediatric dentists $(1 \%) .{ }^{59}$ Thus, the ratio of pediatric specialists to preschool children is very low, $\sim 1: 9,500 .{ }^{10,59}$ To address the shortage of dental workforce in Hong Kong, Faculty of Dentistry, The University of Hong Kong has taken more students with an $\sim 40 \%$ increase in the number of undergraduate dental students since $2016 .{ }^{60}$ The Dental Council of Hong Kong has also increased the fre- quency of licensing examination from once to twice a year for non-locally trained dentists since $2015 .^{61}$

\section{Conclusion}

Although there are some existing governmental and nongovernmental oral health promotion programs for preschool children, dental caries remain prevalent among preschool children in Hong Kong. There is a necessity to revise preventive programs to reduce child oral health disparities. Effective evidence-based community projects including tooth brushing program and topical fluoride treatment in a school setting should be implemented to improve the oral health status of preschool children in a sustainable way.

\section{Disclosure}

The authors report no conflicts of interest in this work.

\section{References}

1. Summers T. The Hong Kong special administrative region at 20: evaluating the Sino-British joint declaration. Asian Education and Development Studies. 2017;7(1):89-101.

2. United Nations Development Programme.org. Dili: human development reports 2018. Available from: http://hdr.undp.org/en/countries/profiles. Accessed September 18, 2018.

3. Data C. New York: Hong Kong GDP per Capital; 2017. Available from: https://www.ceicdata.com/en/indicator/hong-kong/gdp-per-capita. Accessed September 18, 2018.

4. Data C. New York: China GDP per Capital; 2017. Available from: https:// www.ceicdata.com/en/indicator/china/gdp-per-capita. Accessed Sep 18, 2018.

5. Data C. New York: United States GDP per Capital; 2017. Available from: https://www.ceicdata.com/en/indicator/united-states/gdp-per-capita. Accessed September 18, 2018.

6. Food and Health Bureau. Hong Kong special administrative region: ESTIMATES OF HEALTH EXPENDITURE: 1989/90 - 2015/16 Available from: https://www.fhb.gov.hk/statistics/en/dha/dha_summary_report.htm\#A. Accessed December 3, 2018.

7. Census and Statistics Department. Hong Kong special administrative region: population. Available from: https://www.censtatd.gov.hk/hkstat/ sub/so20.jsp. Accessed December 1, 2018.

8. World Population Prospects 2017. New York: World population prospects 2017, data quary. Available from: https://esa.un.org/unpd/wpp/ DataQuery. Accessed September 17, 2018.

9. Census and Statistics Department. Thematic Report: Ethnic Minorities. Hong Kong: The Government of Hong Kong; 2016.

10. Young Children's Development Indicators of HK. Hong Kong special administrative region: The population of 0 - to 5-year-old children from 2012 to 2016 in different districts. Available from: https://www. printfriendly.com/p/g/EW5AxF. Accessed September 25, 2018.

11. Census and Statistics Department. Hong Kong special administrative region: Hong Kong annual digest of statistics, table (section 1-4). Available from: https://www.censtatd.gov.hk/hkstat/sub/sp460. jsp?productCode=B1010003. Accessed September 20, 2018.

12. American Academy of Pediatric Dentistry. Definition of Early Childhood Caries (ECC). Oral Health Policies, and Clinical Guidelines. 2008; $13: 15$.

13. Vos T, Allen C, Arora M, et al. Global, regional, and national incidence, prevalence, and years lived with disability for 310 diseases and injuries, 1990-2015: a systematic analysis for the global burden of disease study 2015. The Lancet. 2016;388(10053):1545-1602. 
14. Neves ÉTB, Firmino RT, de França Perazzo M. Absenteeism among preschool children due to oral problems. J Public Health. 2016;24(1):65-72.

15. Wong KK. Report on a dental survey in Hong Kong 1968. Hong Kong Special Administrative Region: The Government Dental Service and the World Health Organization; 1968.

16. Wei SH, Holm AK, Tong LS, Yuen SW. Dental caries prevalence and related factors in 5-year-old children in Hong Kong. Pediatr Dent. 1993;15(2):4.

17. Chu CH, Fung DS, Lo EC. Dental caries status of preschool children in Hong Kong. Br Dent J. 1999;187(11):616-620.

18. Department of Health. Oral Health Survey 2001. Hong Kong Special Administrative Region: The government of Hong Kong; 2002.

19. $\mathrm{Chu} \mathrm{CH}, \mathrm{Ho} \mathrm{PL}, \mathrm{Lo}$ EC. Oral health status and behaviours of preschool children in Hong Kong. BMC Public Health. 2012;12(1):767.

20. Department of Health. Oral Health Survey 2011. Hong Kong Special Administrative Region: The Government of Hong Kong; 2012.

21. Chen KJ, Gao SS, Duangthip D, Li SKY, Lo ECM, Chu CH. Dental caries status and its associated factors among 5-year-old Hong Kong children: a cross-sectional study. BMC Oral Health. 2017;17(1):121.

22. Kagihara LE, Niederhauser VP, Stark M. Assessment, management, and prevention of early childhood caries. $J$ Am Acad Nurse Pract. 2009;21(1):1-10.

23. Zero DT. Sugars - the arch criminal? Caries Res. 2004;38(3):277-285.

24. Carey CM. Focus on fluorides: update on the use of fluoride for the prevention of dental caries. J Evid Based Dent Pract. 2014;14(Suppl):95-102.

25. Fluoridealert.org. New York: Countries that fluoridate their water. Available from: http://fluoridealert.org/content/bfs-2012/. Accessed September 24, 2018.

26. Census and Statistics Department. The Fertility Trend in Hong Kong, 1981 to 2014. Hong Kong Special Administrative Region: The Government of Hong Kong; 2015.

27. Iheozor-Ejiofor Z, Worthington HV, Walsh T. Water fluoridation for the prevention of dental caries. Cochrane Database Syst Rev. 2015;6(6):CD010856.

28. Beaglehole R, Benzian H, Crail J, Fluoride MJ. In: King J, editor. The Oral Health Atlas: Mapping a Neglected Global Health Issue. Brighton: FDI World Dental Federation; 2009:54-55.

29. Centers for Disease Control and Prevention (CDC). Ten great public health achievements - United States, 1900-1999. MMWR Morb Mortal Wkly Rep. 1999;48(12):241.

30. Evans RW, Stamm JW. Dental fluorosis following downward adjustment of fluoride in drinking water. J Public Health Dent. 1991;51(2): 91-98.

31. Chu CH, Wong SS, Suen RP, Lo EC. Oral health and dental care in Hong Kong. Surgeon. 2013;11(3):153-157.

32. Lo ECM, Wong AHH. Dental fluorosis among Hong Kong children drinking 0.5 ppm fluoridated water. $J$ Dent Res. 2005;84(Sp Iss B):abstract.

33. Jean KJ, Wassef N, Gagnon F, Valcke M. A physiologically-based pharmacokinetic modeling approach using biomonitoring data in order to assess the contribution of drinking water for the achievement of an optimal fluoride dose for dental health in children. Int $J$ Environ Res Public Health. 2018;15(7):1358.

34. Lima YB, Cury JA. Seasonal variation of fluoride intake by children in a subtropical region. Caries Res. 2003;37(5):335-338.

35. U.S. Department of Health and Human Services Federal Panel on Community Water Fluoridation. U.S. public health service recommendation for fluoride concentration in drinking water for the prevention of dental caries. Public Health Rep. 2015;130(4):318-331.

36. Oral Health Education Unit. Hong Kong Special Administrative Region: Tooth Club. Available from: https://www.toothclub.gov.hk/en/ en_home_05.htm. Accessed November 30, 2018.

37. Oral Health Education Unit. Hong Kong Special Administrative Region: "Brighter Smiles for the New Generation" oral care activity at home and school (Original named as Love Teeth with Your Kids Programme). Available from: http://www.toothclub.gov.hk/en/en_home_01_07.html. Accessed November 30, 2018.
38. Cheng D. Oral Health Promotion by the Department of Health. The Hong Kong Medical Diary. 2008;13(11):8-10.

39. Oral Health Education Unit. Hong Kong Special Administrative Region: Brighter Smiles Playland. Available from: http://www.toothclub.gov.hk/ en/en_home_01_04.html. Accessed November 30, 2018.

40. Project Concern. Hong Kong Special Administrative Region: Smiley Action Day. Available from: http://www.projectconcern.org.hk/en/ search/node/Smiley\%20Action\%20Day. Accessed November 30, 2018.

41. Project Concern. Hong Kong Special Administrative Region: Jockey Club Smiley Action Programme Smiley Action Day. Available from: http://www.projectconcern.org.hk/en/node/501. Accessed September 24, 2018.

42. Faculty of Dentistry, The University of Hong Kong. Hong Kong Special Administrative Region: Prevention \& control of tooth decay in kindergarten children. Available from: http://facdent.hku.hk/docs/2013/ KG_Leaflet_EnglishVersion.pdf. Accessed September 24, 2018.

43. Knowledge Exchange, The University of Hong Kong. Hong Kong Special Administrative Region: Preventing Dental Caries for Hong Kong Kindergarten Children. Available from: https://www.ke.hku.hk/ event/preventing-dental-caries-for-hong-kong-kindergarten-children. Accessed December 3, 2018.

44. Fung MHT, Duangthip D, Wong MCM, Lo ECM, Chu CH. Randomized Clinical Trial of $12 \%$ and $38 \%$ Silver Diamine Fluoride Treatment. $J$ Dent Res. 2018;97(2):171-178.

45. Duangthip D, Wong MCM, Chu CH, Lo ECM. Caries arrest by topical fluorides in preschool children: 30 -month results. $J$ Dent. 2018;70:74-79.

46. Lin YC, Wang WC, Chen JH, Chen PH, Lee CH, Huang HL. Significant caries and the interactive effects of maternal-related oral hygiene factors in urban preschool children. J Public Health Dent. 2017;77(3):188-196.

47. National Health Commission of the People's Republic of China. Beijing: The Report of the Fourth National Oral Health Survey Chinese. Available from: http://so.nhfpc.gov.cn/. Accessed September 24, 2018.

48. Monaghan N, Davies GM, Jones CM, Neville JS, Pitts NB. The caries experience of 5-year-old children in Scotland, Wales and England in 2011-2012: reports of cross-sectional surveys using BASCD criteria. Community Dent Health. 2014;31(2):105-110.

49. Blinkhorn AS, Byun R, Johnson G, Metha P, Kay M, Lewis P. The Dental Health of primary school children living in fluoridated, pre-fluoridated and non-fluoridated communities in New South Wales, Australia. BMC Oral Health. 2015;15(1):9.

50. Petersen PE. The World Oral Health Report 2003: continuous improvement of oral health in the 21st century - the approach of the WHO Global Oral Health Programme. Community Dent Oral Epidemiol. 2003;31(Suppl 1):3-24.

51. Department of Health. Hong Kong Special Administrative Region: List of Clinics and Health Centres. Available from: http://www.dh.gov.hk/ english/tele/tele_chc/tele_chc_dcgps.html. Accessed September 24, 2018.

52. Childsmile. Scotland: Childsmile Core. Available from: http://www. child-smile.org.uk/professionals/about-childsmile/childsmile-core. aspx. Accessed December 1, 2018.

53. Pitts NB, Boyles J, Nugent ZJ, Thomas N, Pine CM. The dental caries experience of 5-year-old children in Great Britain (2005/6). Surveys co-ordinated by the British association for the study of community dentistry. Community Dent Health. 2007;24(1):59-63.

54. Jones CM, Davies GM, Monaghan N, Morgan MZ, Neville JS, Pitts NB. The caries experience of 5 year-old children in Scotland in 2013-2014, and in England and Wales in 2014-2015. Reports of cross-sectional dental surveys using BASCD criteria. Community Dent Health. 2017;34(3):157-162.

55. Gao SS, Zhao IS, Hiraishi N, et al. Clinical trials of silver diamine fluoride in arresting caries among children. JDR Clin Trans Res. 2016;1(3):201-210.

56. Duangthip D, Jiang M, Chu CH, Lo EC. Non-surgical treatment of dentin caries in preschool children - systematic review. BMC Oral Health. 2015;15:44. 
57. CrystalYO, Marghalani AA, Ureles SD, et al. Use of silver diamine fluoride for dental caries management in children and adolescents, including those with special health care needs. Pediatr Dent. 2017;39(5):135-145.

58. The Dental Council of Hong Kong. Hong Kong Special Administrative Region: List of Registered Dentists of the Dental Council of Hong Kong Available from: http://www.dchk.org.hk/docs/List_of_Registered_Dentists_Local.pdf. Accessed December 3, 2018.

59. The Dental Council of Hong Kong. Hong Kong Special Administrative Region: Specialist Register of the Dental Council of Hong Kong. Available from: http://www.dchk.org.hk/docs/SE_Paediatric_Dentistry. pdf. Accessed September 24, 2018.
60. The University of Hong Kong. Hong Kong Special Administrative Region: HKU Faculty of Dentistry Ranked No.1 in the World. Available from: https://www.hku.hk/press/news_detail_14311.html. Accessed December 4, 2018.

61. Legislative Council of The Hong Kong Special Administrative Region of The People's Republic of China. Hong Kong special administrative region: legislative council panel on health services provision for public dental care services. Available from: https://www.legco.gov.hk/yr1617/english/panels/hs/papers/hs20170717cb2-1843-4-e.pdf. Accessed December 3, 2018.
Clinical, Cosmetic and Investigational Dentistry

\section{Publish your work in this journal}

Clinical, Cosmetic and Investigational Dentistry is an international, peer-reviewed, open access, online journal focusing on the latest clinical and experimental research in dentistry with specific emphasis on cosmetic interventions. Innovative developments in dental materials, techniques and devices that improve outcomes and patient satisfac-

\section{Dovepress}

tion and preference will be highlighted. The manuscript management system is completely online and includes a very quick and fair peerreview system, which is all easy to use. Visit http://www.dovepress. com/testimonials.php to read real quotes from published authors.

Submit your manuscript here: https://www.dovepress.com/clinical-cosmetic-and-investigational-dentistry-journal 